\title{
Supportive care needs and service use during palliative care in family caregivers of patients with advanced cancer: a prospective longitudinal study
}

\author{
Anneke Ullrich ${ }^{1,2}$ (1) $\cdot$ Gabriella Marx ${ }^{3,4} \cdot$ Corinna Bergelt $^{2} \cdot$ Gesine Benze $^{3} \cdot$ Youyou Zhang $^{1} \cdot$ Feline Wowretzko ${ }^{1}$. \\ Julia Heine $^{3} \cdot$ Lisa-Marie Dickel ${ }^{3} \cdot$ Friedemann Nauck $^{3} \cdot$ Carsten Bokemeyer $^{1} \cdot$ Karin Oechsle $^{1}$ (D)
}

Received: 7 August 2019 / Accepted: 5 June 2020 / Published online: 6 July 2020

(C) The Author(s) 2020

\begin{abstract}
Purpose This study aimed to investigate the supportive care needs of family caregivers (FCs) of advanced cancer patients and their support service use at the beginning of specialist inpatient palliative care (SIPC), near the patient's death, and during bereavement.

Methods FCs reported their needs using the Family Inventory of Needs (FIN), along with their utilization of psychosocial and bereavement support services at the beginning $(N=232)$ and 6-9 months after SIPC $(N=160)$.

Results At the beginning of SIPC, mean of 16.9 of 20 needs were reported to be highly important, and 12.2 were reported to be met. At the time of the patient's death, 16.8 needs were highly important, and 13.8 were met. At both time points, the highest ranked need was related to information about changes in the patient's condition (100\% vs. $99 \%)$, and the most frequently unmet need was related to feeling hope (73\% vs. $71 \%$ ). Multivariate linear regression analysis revealed a low education level to be consistently related to a greater number of highly important needs. Higher satisfaction with care and better social support was related to a greater number of met needs. Twenty-five percent of FCs had accessed at least one psychosocial support service prior to SIPC, and 30\% had done so during bereavement. Among non-users of support services, $>75 \%$ indicated sufficient informal support as a barrier to service use.

Conclusions The findings offer a useful guide for adequately addressing FCs' needs in an effort to optimize FC support. However, only a subgroup of the FCs used support services. Better information and provision of tailored services might improve FCs' situations in the future.
\end{abstract}

Anneke Ullrich

a.ullrich@uke.de

Gabriella Marx

g.marx@uke.de

Corinna Bergelt

bergelt@uke.de

Gesine Benze

gesine.benze@med.uni-goettingen.de

Youyou Zhang

youyou.zhang@stud.uke.uni-hamburg.de

Feline Wowretzko

feline.wowretzko@stud.uke.uni-hamburg.de

Julia Heine

julia.heine@stud.med.uni-goettingen.de
Friedemann Nauck

friedemann.nauck@med.uni-goettingen.de

Carsten Bokemeyer

c.bokemeyer@uke.de

Karin Oechsle

kaoechsl@uke.de

1 Palliative Care Unit, Department of Oncology, Hematology and BMT, University Medical Center Hamburg-Eppendorf, Martinistr, 5220246 Hamburg, Germany

2 Department of Medical Psychology, University Medical Center Hamburg-Eppendorf, Hamburg, Germany

3 Department of Palliative Medicine, University Medical Center Goettingen, Goettingen, Germany

4 Department of General Practice/Primary Care, University Medical Center Hamburg-Eppendorf, Hamburg, Germany 
Keywords Family caregiver $\cdot$ Cancer $\cdot$ Palliative care $\cdot$ Needs $\cdot$ Support services $\cdot$ Prospective studies

\section{Introduction}

Family caregivers (FCs) support patients with advanced cancer but are also affected by the patient's disease themselves and experience specific but often unmet supportive care needs. In a current review, the most commonly identified unmet needs for informal caregivers were information needs, including illness and treatment information (26-100\%) and care-related information (21-100\%) [1]. Additional frequently reported unmet $\mathrm{FC}$ needs were education in symptom management and care [2-5], daily living needs [6, 7], dealing with prognostic uncertainty [7-10], and reducing the patient's stress $[7,11]$. Fringer et al. suggested maintaining normality during transitions to be the central need of patients and their FCs [12]. The main categories of FC needs were found to be social, cognitive, and psychological needs [13] as well as knowledge and competence, preparedness, and role confidence [14]. While the number of needs seem to remain stable over time, specific needs seem to be time dependent: Managing difficult aspects of the patient's behavior and adjusting to changes in the patient's personality seem to increase over time [7], while the "need for knowledge about the disease" and other information needs seem to decrease over time [9]. Studies showed that after the patient's death, FCs claimed that their own needs had not been adequately addressed during the patient's disease and that support was insufficient $[15,16]$. Bereaved FCs also reported a lack of bereavement support and emotional assistance [16] or impersonal, generic, or just standard practice bereavement support [15].

Higher numbers of unmet needs were associated with psychological distress in FCs $[7,11]$ and overall FC burden $[2$, 17, 18]. Further need-related factors with a negative impact on FCs' burden were a lack of care training, low available support, a large discrepancy between FCs' and patient's reports of patient's unmet need, as well as assistance managing medical, non-medical care and direct patient care activities [4, 17, 19]. Overall, the impact of FCs' sociodemographic characteristics on their supportive needs seems to be low according to the current literature [11], but there might be some effects of partnership and financial aspects [20,21]. In contrast, satisfaction with patient care seems to be important for the perception of one's own unmet needs in FC [2, 22]. Studies have suggested that FCs' needs might be more likely to be met when the patient is treated in a specialist palliative care setting [23], and some studies have distinguished specific aspects contributing to potential benefits as well as relevant deficits [24-28]. However, the impact of palliative care on FCs' needs remains controversial [29].
Support service utilization in FC has rarely been investigated, but Dionne-Odom et al. reported a utilization rate of approximately one-third [30]. In this study, depressive symptoms, anxiety, and preparedness were associated with utilization and FCs' interest in such services [30]. Interest in services also seemed to depend on the number of supportive care needs [11], minority status, shorter duration of caregiving, and higher stress burden [30]. However, Aoun et al. found that the most frequently used sources of support for FC were informal sources, such as family, friends, and funeral providers. Professional sources were the least used and were related to the highest proportions of perceived unhelpfulness, whereas unhelpfulness was perceived lower for informal support [31].

Overall, data on the needs of FCs caring for an advancedcancer patient in the SIPC setting, factors associated with need profiles, and the utilization of support services are rare and heterogeneous. Therefore, the aims of this multicenter study were to prospectively investigate (1) the importance and satisfaction of needs among FCs of patients with advanced cancer at the beginning of specialist inpatient palliative care (SIPC), near the patient's death and during bereavement; (2) factors associated with the amount of important and met needs; and (3) FCs' utilization of psychosocial support and bereavement services.

\section{Methods}

\section{Sample and design}

Between June 2016 and June 2017, FCs were consecutively recruited in two university medical centers within $72 \mathrm{~h}$ after the advanced cancer patient's first admission to the SIPC ward. Inclusion criteria included being the primary informal caregiver as indicated by the patient and being over the age of 18. The exclusion criteria were imminent death, legal guardianship, and inadequate language skills or cognitive impairment that would interfere with giving fully informed consent and completing questionnaires.

Data were collected at two time points by self-report questionnaires. The FC situation at the beginning of SIPC was assessed within $72 \mathrm{~h}$ after admission (T1), and nonrespondents were personally reminded after 2 working days. The second assessment was performed 6 months after the patient's discharge from or death on the SIPC ward (T2). Among the FCs of patients who were alive after 6 months, the second assessment was postponed up to a maximum of 9 months. Non-respondents received a written reminder after approximately 4 weeks. 


\section{Instruments}

\section{Outcome variables (T1 and $\mathrm{T} 2$ )}

Supportive care needs To assess needs at the beginning of SIPC (T1) and needs experienced within the last 7 days of the patient's life (retrospective rating, T2), FCs completed a German version of the 20-item Family Inventory of Needs (FIN) [32, 33]. On the FIN, needs are rated on two subscales, FIN-Importance (1 "not important" to 5 "extremely important") and FIN-Fulfillment (0 "not met," 0.5 "partly met," and 1 "met"), with the score for the latter subscale only calculated for needs indicated to be at least "somewhat important." To estimate needs related to preparedness and psychosocial assistance, 7 items were added to the FIN questionnaire.

Utilization of support services FCs reported their use of sources of information and support prior to SIPC (assessed at T1) and after the patient's death (assessed at T2), their perceived helpfulness of accessed services, and barriers to using psychosocial support services. Additionally, data on the utilization of bereavement care provided by the two study wards, which included open bereavement cafés, commemoration ceremonies, and counseling on external, locally available bereavement care, were collected (assessed at T2).

\section{Baseline factors potentially related to supportive care needs (T1)}

Subjective psychological distress The Distress Thermometer (DT) is an analogue scale rated from 0 "no distress" to 10 "extreme distress," with values $\geq 5$ indicating a relevant burden with the need for professional psychosocial support [34]. The DT was validated for distress screening in FCs in a previous study, which indicated the same cut-off value of $\geq 5$ [35]. In addition to the DT, an adapted problem list including assessment of physical strain was administered [36].

Depressive and anxiety symptoms FCs completed the Patient Health Questionnaire-Depression module (PHQ-9 [37]) and the General Anxiety Disorder Scale (GAD-7 [38]), which have total scores ranging from 0 to 27 and 0 to 21 , respectively.

Palliative care outcome FCs' multidimensional perspectives on the patient's situation were assessed by a caregiver-adapted version of the 7-day recall staff version of the Integrated Palliative Care Outcome Scale (IPOS) [39], which has a total score ranging from 0 to 68 .

Satisfaction with care Satisfaction with team-based services, including symptom relief, information, FC support, and patient psychosocial care, was assessed by using the Family Carer Satisfaction with Palliative Care scale (FAMCARE-2) [40, 41], which has a total score ranging from 17 to 85 .

For the DT, GAD-7, PHQ-9, and IPOS, higher values indicate worse outcomes. For the FAMCARE-2, a higher score reflects higher satisfaction.

Sociodemographic-, medical-, and care-related variables FCs reported their own and the patient's sociodemographic characteristics; their relationship to the patient; and information relating to the patient's diagnosis, care, and death. FCs' socioeconomic status was assessed using a composite indicator score [42], and migrant background was assessed using a basic set of indicators for mapping migrant status [43]. FCs' social support was measured by the Oslo-3-Item-Social-Support Scale (OSLO-3). The total score ranges from 3 to 14 , with categorization into poor (3-8), moderate (9-11), and strong (12-14) support [44, 45].

\section{Statistical analysis}

Descriptive statistics were calculated, including the frequency distributions, percentages, means, and standard deviations.

For both time points, explorative multivariate linear regression analyses using backwards variable selection procedures were conducted, with the number of very/ extremely important needs and the number of needs met being the dependent variables. In the regression analyses, the same set of independent baseline variables (measured at T1) were included at step 1: FC characteristics (age, gender, relationship to the patient, religious confession, education, socioeconomic status, work status, and social support), patient- and care-related variables (patient age, time since diagnosis, prior care site, and $\mathrm{FCs}$ ' prior involvement in caregiving), prior use of psychosocial support services, satisfaction with care, and palliative care outcome as well as FCs' physical and mental strain (exhaustion, sleep disturbances, distress, and depressive and anxiety symptoms). Categorical variables were dichotomized. The examination of correlations among independent variables revealed no problems with multicollinearity, except for working situation and FCs' age and depressive and anxiety symptoms. Thus, working situation and depressive symptoms were omitted from further analysis. Missing data were handled using the listwise deletion method.

All significance tests were two-sided using a significance level of $\alpha<0.05$. All analyses were performed using the statistical package SPSS version 24.0 (IBM, USA). 


\section{Results}

\section{Sample recruitment and characteristics}

\section{Recruitment procedures}

A total of 438 FCs met the inclusion criteria. Of these FCs, 287 agreed to participate $(66 \%)$, and 232 (response rate: $81 \%$ ) returned the first questionnaires (T1). At follow-up (T2), 160 FCs returned the second questionnaire (response rate: $77 \%$ ). Details are presented in Fig. 1. The mean time between T1 and T2 was 6.7 months.

\section{Non-respondent analyses}

Comparing respondents to non-respondents, we did not find significant differences in sociodemographic characteristics (age, gender, marital status, educational level, working situation, socioeconomic status, and relationship to the patient assessed at $\mathrm{T} 1 ; p=0.058$ to 0.854 ) or in psychological burden (distress, anxiety symptoms, and depressive symptoms at $\mathrm{T} 1 ; p=0.358$ to 0.863 ).

\section{Sample characteristics}

The mean age of the 232 FCs was $55.5 \pm 14.8$ years (T1); female FCs constituted $66 \%$ of the sample, and spouses/partners constituted $64 \%$. The time since the patient's diagnosis was $\leq 12$ months in $43 \%$ of cases (Table 1). At the second assessment (T2), the mean time since patient death was 6.0 months (SD 1.4; range, 1-9), and 96 out of 160 patients $(60 \%)$ had died at the SIPC ward (not shown).
Fig. 1 Study recruiting process and sample development

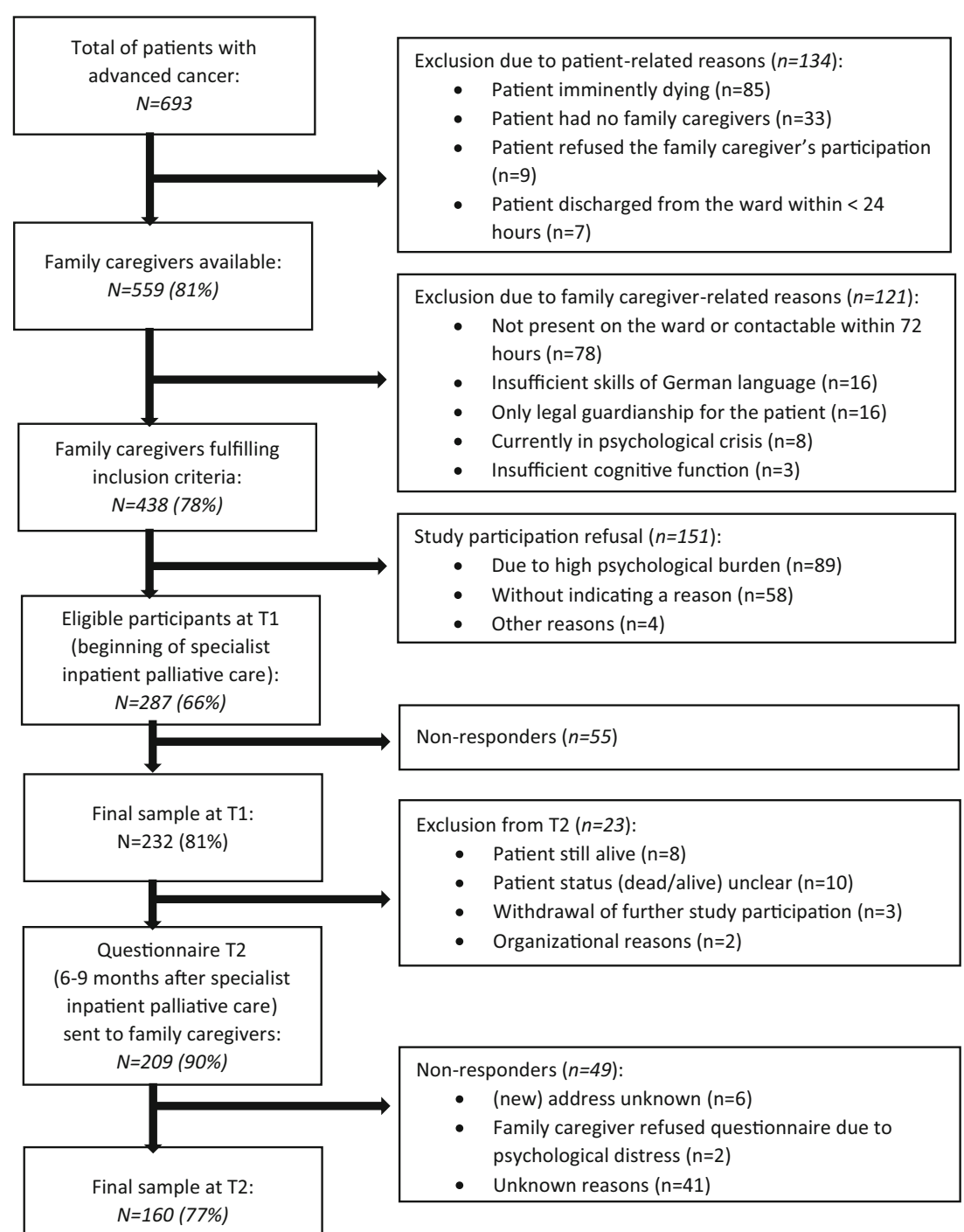


Table 1 Sample characteristics and family caregivers mental burden, palliative care outcome and satisfaction with care at the beginning of SIPC (T1; $N=232$ )

\section{Family caregiver characteristics}

Age, M (SD); range

Relationship to the patient. Patient is..., $n(\%)$

Marital status, $n(\%)$

Having Children, $n(\%)$

Religious confession, $n(\%)$

Migrant background, $n(\%)$

Educational level, $n(\%)$

Current working situation, $n(\%)$

Socioeconomic status, $n(\%)$

Perceived social support (OSLO-3), M (SD); range

Perceived social support categories (OSLO-3), $n(\%)$

Patient- and care-related characteristics

Patient's gender, $n(\%)$

Patient age, $n(\%)$

Time from patient's diagnosis, $n(\%)$

Prior care site, $n(\%)$
Spouse/partner

55.5 (14.8); 20-88

Mother/father

148 (63.8)

Others ${ }^{\text {a }}$

$61(26.3)$

Single

$23(9.9)$

Married or life partnership

36 (15.5)

164 (70.7)

Divorced or widowed

29 (12.5)

Missing

3 (1.3)

Yes

164 (70.7)

No

24 (27.6)

Missing

Yes

4 (1.7)

153 (65.9)

75 (32.3)

No

Missing

4 (1.7)

None

$212(91.4)$

First generation

15 (6.5)

Second generation

$5(2.2)$

Elementary school ( $\leq 9$ years)

65 (28.0)

Junior high school (10 years)

$72(31.0)$

High school (12-13 years)

$91(39.2)$

Missing

4 (1.7)

Working

$123(53.0)$

Not working

99 (42.7)

Missing

$10(4.3)$

Low

44 (19.0)

Moderate

$111(47.8)$

High

$73(31.5)$

Missing

4 (1.7)

10.7 (2.3); 4-14

Poor

Moderate

43 (18.5)

90 (38.8)

Strong

Missing

98 (42.2)

$1(0.4)$

Male

118 (50.9)

Female

105 (45.3)

Missing

9 (3.9)

$\leq 60$ years

75 (32.3)

$>60$ years

155 (66.8)

Missing

$2(0.9)$

$\leq 12$ months

99 (42.7)

$>12$ months

125 (53.9)

Missing

8 (3.4)

82 (35.3)

21 (9.1)

33 (14.2)

82 (35.3)

$11(4.8)$ 
Table 1 (continued)

Family caregiver characteristics

\begin{tabular}{|c|c|c|}
\hline & Missing & $3(1.3)$ \\
\hline \multirow[t]{2}{*}{ Existence of a patient decree, $n(\%)$} & Yes & $140(60.3)$ \\
\hline & No & $92(39.7)$ \\
\hline \multirow[t]{2}{*}{ Existence of a power of attorney ${ }^{\mathrm{c}}, \mathrm{n}(\%)$} & Yes & $159(68.5)$ \\
\hline & No & $73(31.5)$ \\
\hline \multirow[t]{3}{*}{ Prior involvement of the family caregiver in patient care, $n(\%)$} & Yes & $107(46.1)$ \\
\hline & No & $118(50.9)$ \\
\hline & Missing & $7(3.0)$ \\
\hline \multicolumn{3}{|l|}{ Family caregivers physical and mental burden } \\
\hline \multirow[t]{3}{*}{ Exhaustion, $n(\%)$} & Yes & $171(73.7)$ \\
\hline & No & $51(22.0)$ \\
\hline & Missing & $10(4.3)$ \\
\hline \multirow[t]{3}{*}{ Sleep disturbances, $n(\%)$} & Yes & $163(70.3)$ \\
\hline & No & $60(25.9)$ \\
\hline & Missing & $9(3.9)$ \\
\hline Distress (DT), M (SD); range & & $7.9(1.8) ; 0-10$ \\
\hline Anxiety symptoms (GAD-7), M (SD); RANGE & & $9.4(5.1) ; 0-21$ \\
\hline Depressive symptoms (PHQ-9), M (SD); Range & & $9.0(5.7) ; 0-27$ \\
\hline \multicolumn{3}{|l|}{ Family caregivers assessment of palliative care } \\
\hline Palliative care outcome (IPOS), M (SD); Range & & $37.9(7.7) ; 12-58$ \\
\hline Satisfaction with care (FAMCARE-2), M (SD); range & & $73.7(9.6) ; 44-85$ \\
\hline
\end{tabular}

$M$, Mean; SD, standard deviation; $F C$, family caregiver; SIPC, specialist inpatient palliative care; OSLO-3, OSLO-3-Item-Social-Support Scale; $D T$, Distress Thermometer; $G A D-7$, General Anxiety Disorder Scale; $P H Q-9$, Patient Health Questionnaire-Depression module; IPOS, Integrated Palliative Outcome Scale; FAMCARE-2, Family Caregiver Satisfaction with Palliative Care scale

${ }^{a}$ Adult children, siblings, close friends or other relatives; ${ }^{b}$ Nursing home in 9 patients or other care facilities; ${ }^{\mathrm{c}}$ The patient had appointed the family caregiver to act as substitute decision-maker in terms of personal (including health) matters. Thus, the family caregiver was permitted under the law to make decisions on behalf of the patient regarding medical decisions, if the patient lacked decision-making capacity

\section{Importance and fulfillment of supportive care needs among family caregivers}

\section{Beginning of SIPC (T1)}

FCs rated a mean number of 16.9 of 20 needs $(85 \%)$ to be very/extremely important (FIN-Importance; SD 2.6; range, 820 ). The highest ranked need was related to information about changes in the patient's condition (100\%), and the lowest ranked need concerned the FC's own welfare (27\%). The mean number of met needs was 12.2 of 20 (FIN-Fulfillment; SD 5.4, range 0-20), representing $60 \%$ of needs (not shown). However, seven needs were unmet in more than $50 \%$ of participants, with needs related to hope $(73 \%)$ and knowing when to expect symptoms $(63 \%)$ being the most common unmet needs (Table 2).

\section{Last 7 days of the patient's life (T2)}

FCs retrospectively rated a mean number of 16.8 needs to be very/extremely important (FIN-Importance; SD 3.1; range, 7 -
20), representing $85 \%$ of needs (not shown). Again, the need that was indicated to be most important was being informed about changes in the patient's condition (99\%), and the least important was related to the FC's own welfare (31\%). Overall, a mean number of 13.8 needs were met (FIN-Fulfillment; SD 4.8 , range $3-20$ ), representing $70 \%$ of needs. Three needs remained unmet in more than $50 \%$ of participants. Again, needs related to hope $(71 \%)$ and knowing when to expect symptoms $(55 \%)$ were most frequently unmet (Table 2 ).

\section{Baseline factors associated with numbers of highly important and met needs}

\section{Beginning of SIPC (T1)}

In order of magnitude, FC's lower education, FC's older age, patient's home-based care prior to SIPC, and patient's higher distress were associated with a higher number of very/ extremely important needs (FIN-Importance; $\beta=0.148$ to $0.235 ; p=0.004$ to 0.043 ). Factors associated with higher numbers of met needs were FC's higher satisfaction with care, 


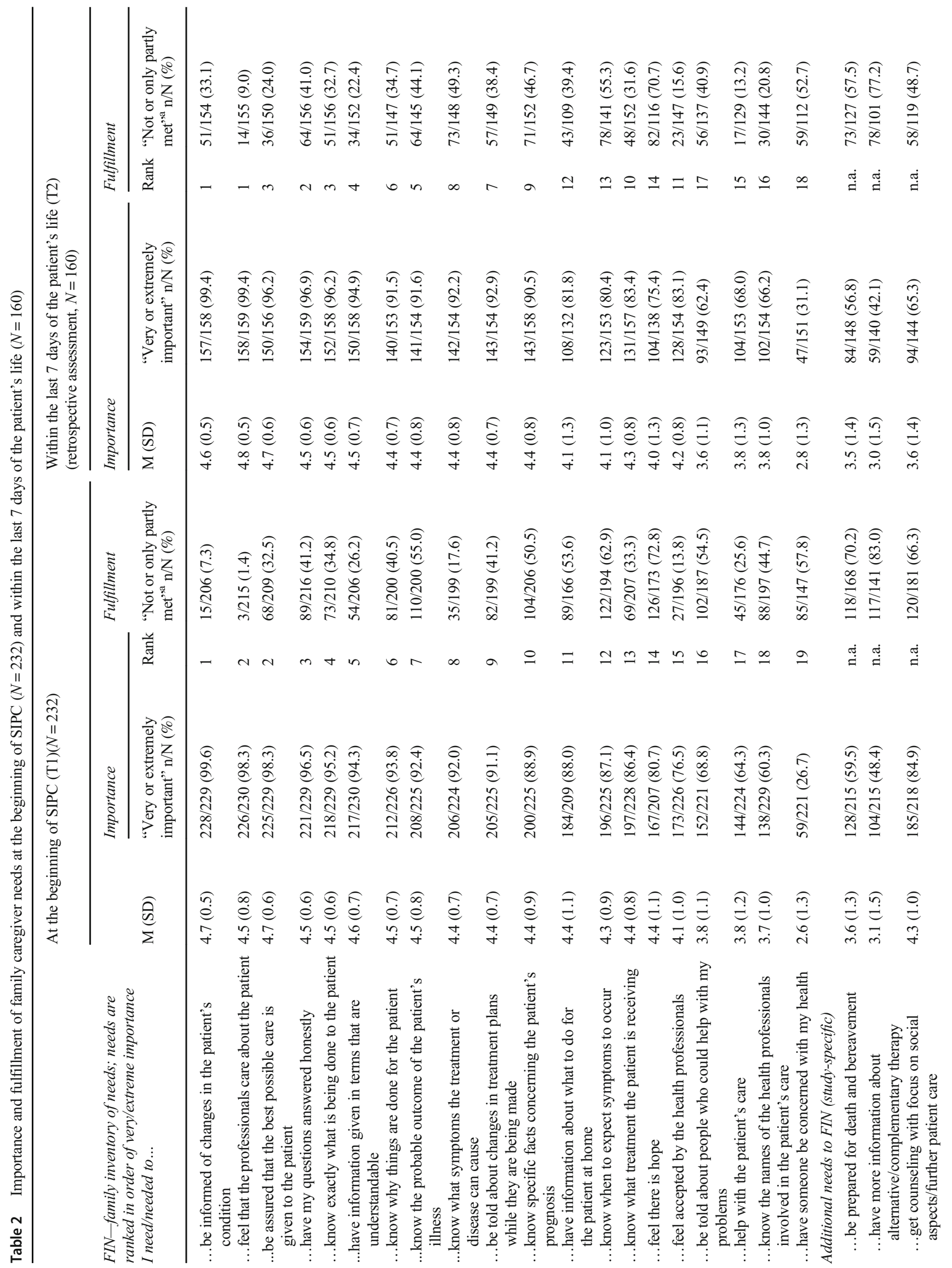


FC not being appointed as a substitute decision-maker, FC's stronger social support, patient's diagnosis $\leq 1$ year prior to SIPC, and FC's better assessment of the palliative care outcome (FIN-Fulfillment; $\beta=-0.120$ to $0.580 ; p<0.001$ to $0.037)$. The final models accounted for $25 \%$ of the variance in the number of important needs and 53\% of the variance in the number of met needs (Table 3 ).

\section{Last 7 days of the patient's life (T2)}

In order of magnitude, FC's lower education, FC's low socioeconomic status, FC's lack of utilization of support services prior to SIPC, and patient's diagnosis $\leq 1$ year prior to SIPC were related to a higher number of very/extremely important needs (FIN-Importance; $\beta=0.186$ to $-0.321 ; p=0.002$ to $0.045)$. Factors associated with a higher number of met needs were FC's higher care satisfaction, FC's stronger social support, and FC not being appointed as a substitute decisionmaker (FIN-Fulfillment; $\beta=-0.222$ to $0.343 ; p=0.005$ to 0.032). The final models accounted for $38 \%$ of the variance in the number of important needs and $35 \%$ of the variance in the number of met needs (Table 3).

\section{Use of psychosocial and bereavement support services}

\section{Use of psychosocial support services prior to SIPC (T1)}

Prior to the patient's admission to the SIPC ward, $25 \%$ of FCs had used at least one source of information or support. The most frequently accessed service was psychological counseling, which was used by $16 \%$ of FCs. Overall, 58 FCs had accessed 108 services, which were rated "helpful" (vs. not) in $60 \%$ of cases. Among 174 non-users, the strongest barrier was sufficient informal support (85\%; Table 4).

\section{Use of psychosocial and bereavement services after the patient's death (T2)}

During bereavement, 46 (36\%) FCs reported using bereavement services provided by the two study wards, with commemoration ceremonies being the most commonly used service (21\%). Among only the FCs of the 96 patients who had died on the study ward, approximately half used the wards' bereavement services. Beyond these services, $30 \%$ of this subgroup of FCs had accessed at least one external source of information and support, with bereavement care (11\%) and psychological counseling (11\%) being the most frequent. In total, 48 FCs had accessed 87 support services, which were rated "helpful" in $90 \%$ of cases. Among 112 non-users, the most frequent barrier was sufficient informal support (78\%; Table 4). 
Table 3 Factors associated with family caregiver needs at admission to SIPC (T1; N =232) and within the last 7 days of the patient's life (T2; $\mathrm{N}=160)$

\begin{tabular}{|c|c|c|c|c|c|c|c|c|}
\hline & \multicolumn{4}{|c|}{$\begin{array}{l}\text { At the beginning of SIPC } \\
(\mathrm{N}=232)^{\mathrm{a}, \mathrm{b}}\end{array}$} & \multicolumn{4}{|c|}{$\begin{array}{l}\text { Within the last } 7 \text { days of the } \\
\text { patient's life (retrospective } \\
\text { assessment, } N=160 \text { ) }\end{array}$} \\
\hline & $\mathrm{b}$ & S.E. $b$ & ß & $\mathrm{p}$ & $\mathrm{b}$ & S.E. $b$ & $\beta$ & $\mathrm{p}$ \\
\hline \multicolumn{9}{|l|}{ Regression models for number of very/extremely important needs ${ }^{e}$} \\
\hline FC's age & .036 & .014 & .204 & $.012 *$ & $\ddagger$ & & & \\
\hline FC's education [up to junior high school = 0 ; high school $=1$ ] & -.1 .154 & .391 & -.235 & $.004 *$ & -2.021 & .621 & -.321 & $.002 *$ \\
\hline FC's socioeconomic status [moderate/high $=0$; low $=1]$ ] & $\dagger$ & & & & 2.231 & .806 & .272 & $.007^{*}$ \\
\hline Relationship to the patient [others $=0 ;$ spouse/partner $=1]$ & & & & & 1.087 & .606 & .173 & .077 \\
\hline Time since patient's cancer diagnosis prior to SIPC $[>1$ year $=0 ; \leq 1$ year $=1]$ & \pm & & & & 1.156 & .567 & .186 & $.045^{*}$ \\
\hline Care site prior to SIPC $[$ others $=0 ;$ at home $=1]$ & .962 & .379 & .195 & $.012 *$ & $\ddagger$ & & & \\
\hline FC's assessment of the palliative care outcome (IPOS) & 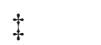 & & & & .074 & .039 & .167 & .063 \\
\hline Utilization of support services prior to SIPC [yes $=0 ;$ no $=1]$ & 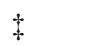 & & & & 1.759 & .673 & .247 & $.011 *$ \\
\hline Distress (DT) & .262 & .128 & .173 & $.043 *$ & $\ddagger$ & & & \\
\hline Anxiety symptoms (GAD-7) & .070 & .040 & .148 & .083 & $\ddagger$ & & & \\
\hline \multicolumn{9}{|l|}{ Regression models for number of met needs ${ }^{e}$} \\
\hline FC's religious confession $[$ no $=0 ;$ yes $=1]$ & -.1311 & .761 & -.120 & .088 & $\$$ & & & \\
\hline FC's education [up to junior high school $=0$; high school $=1$ ] & 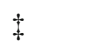 & & & & -2.300 & 1.156 & -.216 & .051 \\
\hline Time since patient's cancer diagnosis prior to SIPC $[>1$ year $=0 ; \leq 1$ year $=1]$ & 1.563 & .721 & .150 & $.033 *$ & 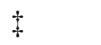 & & & \\
\hline Existence of power of attorney $[\mathrm{no}=0 ;$ yes $=1]$ & -1.980 & .792 & -.171 & $.014 *$ & -2.705 & 1.237 & -.222 & $.032 *$ \\
\hline Involvement in patient care prior to SIPC $[\mathrm{no}=0 ;$ yes $=1]$ & \pm & & & & -1.828 & 1.060 & -.176 & .089 \\
\hline FC's assessment of the palliative care outcome (IPOS) & -.100 & .048 & -.144 & $.037 *$ & $\ddagger$ & & & \\
\hline FC's satisfaction with palliative care (FAMCARE-2) & .287 & .035 & .580 & $<.001 *$ & .189 & .057 & .343 & $.001 *$ \\
\hline Perceived social support (OSLO-3) & .425 & .175 & .168 & $.017 *$ & .706 & .257 & .286 & $.008^{*}$ \\
\hline
\end{tabular}

Abbreviations: b, Beta; S.E. b, standardized error; $\beta$, standardized b; $p$ value, probability of type I error; SIPC, specialist inpatient palliative care; IPOS, Integrated Palliative Care Outcome Scale (higher values indicate worse palliative care outcome); FAMCARE-2, Family Caregiver Satisfaction with Palliative Care Scale (higher values indicate higher satisfaction); DT, Distress Thermometer (higher values indicate higher distress); OSLO-3, OSLO-3Item-Social-Support Scale (higher values indicate stronger social support)

${ }^{\mathrm{a}}$ Number of very/extremely important needs at the beginning of SIPC: $\mathrm{R}^{2}=.254, \mathrm{~F}(5,129)=8.773, p<.001$; Tolerance values between $.804-985$

${ }^{\mathrm{b}}$ Number of met needs at the beginning of SIPC: $\mathrm{R}^{2}=.527, \mathrm{~F}(6,102)=18.964, \mathrm{p}<.001$; Tolerance values between $.957-.991$

${ }^{\mathrm{c}}$ Number of very/extremely important needs within the last 7 days of the patient's life: $\mathrm{R}^{2}=.378, \mathrm{~F}(6,80)=8.103$, $\mathrm{p}<.001$; Tolerance values between $.799-.984$

${ }^{\mathrm{d}}$ Number of met needs within the last 7 days of the patient's life: $\mathrm{R}^{2}=.346, \mathrm{~F}(5,67)=7.101, \mathrm{p}<.001$; Tolerance values between $.828-.944$

${ }^{\mathrm{e}}$ All potential predictor variables were measured at the beginning of SIPC (T1)

\$ Not included in the final regression model due to stepwise backwards selection procedure

*All significant $p$-values are marked with an asterisks

\section{Discussion}

In this prospective multicenter study, FCs indicated a consistently high rate of approximately $85 \%$ of needs being very/ extremely important (FIN-Importance) at the beginning of SIPC as well as at the time the patient was dying. Interestingly, the importance of specific FC needs did not change substantially over time; the following FC needs remained the top five needs over time: "being informed of changes in the patient's condition," "feeling that the health professionals care well for the patient," "being assured the best possible care is being given to the patient," "having my questions answered honestly," and "knowing exactly what is being done to the patient." In contrast, two studies with FCs of patients with neuro-oncological tumors suggested that the quality of FC needs changes during the patient's disease trajectory $[7,9]$, which was not confirmed in our study. However, neither study evaluated FCs at a time when the patient was nearing death.

At the beginning of SIPC, the mean rate of met needs (FINFulfillment) was $60 \%$. A previous study described a comparable rate of met needs in $67 \%$ of FCs in a palliative care setting [23]. In our study, the mean percentage of met needs increased slightly to $70 \%$ at the time the patient was dying. This finding indicates that approximately $30-40 \%$ of needs were unmet from a longitudinal perspective, which seems 
Table 4 Family caregivers utilization of support services prior SIPC $(\mathrm{T} 1 ; N=232)$ and after the patient's death $(\mathrm{T} 2 ; N=160)$

\begin{tabular}{|c|c|c|}
\hline & $\begin{array}{l}\text { Prior to SIPC (T1) }(\mathrm{N}=232) \\
\mathrm{n} / \mathrm{N}(\%)\end{array}$ & $\begin{array}{l}\text { After the patient's death }(\mathrm{T} 2)(\mathrm{N}=160) \\
\mathrm{n} / \mathrm{N}(\%)\end{array}$ \\
\hline Utilization of $\geq 1$ support service, $n(\%)$ yes ${ }^{\text {a }}$ & $58 / 232(25.0 \%)$ & $48 / 160(30.0)$ \\
\hline \multicolumn{3}{|l|}{ Support services used (multiple answers possible), $\mathrm{n}(\%)$ yes } \\
\hline Psychological counseling & $38 / 232(16.4)$ & $17 / 160(10.6)$ \\
\hline Social counseling & $15 / 232(6.5)$ & $14 / 160(8.8)$ \\
\hline Spiritual counseling & $15 / 232(6.5)$ & $12 / 160(7.5)$ \\
\hline Counseling on parenting/family issues & $10 / 232(4.3)$ & $2 / 160(1.3)$ \\
\hline Counseling at cancer information center & $13 / 232(5.6)$ & $4 / 160(2.5)$ \\
\hline Self-help group & $8 / 232(3.4)$ & $9 / 160(5.6)$ \\
\hline Bereavement care ${ }^{\mathrm{b}}$ & n.a. & $18 / 160(11.3)$ \\
\hline Utilization of $\geq 1$ bereavement support provided by the study wards, $\mathrm{n}(\%)$ yes & n.a. & $46 / 127(36.2)$ \\
\hline \multicolumn{3}{|l|}{ Study wards' bereavement support used (multiple answers possible), $\mathrm{n}(\%)$ yes ${ }^{\mathrm{c}}$} \\
\hline Commemoration ceremony & n.a. & $25 / 119(21.0)$ \\
\hline Open bereavement café & n.a. & $12 / 116(10.3)$ \\
\hline Counseling for locally available, external bereavement care & n.a. & $6 / 114(8.3)$ \\
\hline \multicolumn{3}{|c|}{ Barriers for accessing support services in non-users (multiple answers possible), $\mathrm{n}(\%)$ yes ${ }^{\mathrm{d}}$} \\
\hline Sufficient informal support & $129 / 152(84.9)$ & 73/94 (77.7) \\
\hline No subjective need & $107 / 150(71.3)$ & $55 / 93(59.1)$ \\
\hline Lack of time & $64 / 142(45.1)$ & 24/87 (27.6) \\
\hline Preferring support by treating physicians & $65 / 143(45.5)$ & 28/88 (31.8) \\
\hline No expectation of subjective benefit & 49/134 (36.6) & $39 / 85(45.9)$ \\
\hline Lack of knowledge about psychosocial services & $50 / 146(34.2)$ & $27 / 90(30.0)$ \\
\hline Services too far away & $28 / 139(20.1)$ & $20 / 85(23.5)$ \\
\hline Potential burden to family/partnership & $5 / 142(3.5)$ & $9 / 88(10.2)$ \\
\hline
\end{tabular}

Abbreviations: SIPC, specialist inpatient palliative care; n.a., not applicable

${ }^{a}$ Including external bereavement services and those of the study wards after the patient's death; ${ }^{\mathrm{b}}$ Only external bereavement services; ${ }^{\mathrm{c}}$ Services only provided at one study ward are not displayed; ${ }^{\mathrm{d}}$ Only family caregivers who reported not having accessed any service at respective times were included (T1: $N=174 ; \mathrm{T} 2: N=112$ )

alarming since the unsolved problems or unmet needs of FCs can negatively affect their own quality of life as well as patient health outcomes [46]. On the other hand, the number of needs unmet in more than $50 \%$ of FCs decreased from 7 to 3 out of 20 needs over time. Notably, the remaining three needs had already been unmet at the beginning of SIPC. These unmet needs were related to hope, knowledge of when to expect the occurrence of symptoms and the FC's own welfare.

A comparison of the satisfaction of specific needs at the beginning of SIPC and at the time of the patient's death showed that some needs changed in more than $15 \%$ of FCs, which might be interpreted as clinically relevant. The particularly affected needs were "being informed of changes in the patient's condition" (7\% unmet at beginning of SIPC vs. $33 \%$ at time of patient's death) and "knowing what symptoms the treatment or disease can cause" (18\% vs. $49 \%)$. When patients enter SIPC, information about the patient's health status and cause of symptoms might be most explicitly and extensively discussed during the first clinical encounters with FCs. However, FCs do not receive such information later in the care process, as demonstrated by our results. In contrast, the rates of unmet needs decreased substantially with regard to having information about people who could help with FCs' problems (55\% vs. $41 \%$ ) and knowing the names of the members palliative care team ( $45 \%$ vs. $21 \%)$. Several studies reported unmet needs of FCs during the patient's disease, which primarily concerned information, symptom management and medication, patient care, and FC needs regarding day-to-day life in light of the patient's disease $[2-4,6]$. Additional studies evaluated FCs' perspectives after the patient's death retrospectively and indicated a lack of fulfillment of needs, with $30-50 \%$ of FCs complaining of a lack of interest in their emotional and psychological distress pre-bereavement, a lack of or little information about the prognosis or disease trajectory, or a lack of FC-directed support offers $[15,16]$. In many aspects, our results support these findings but add the dimension of spiritual needs, as feeling hope was a consistently important and often unmet need in FCs over time. Albeit to a lesser extent, preparedness for death and bereavement, which could also 
be seen as spiritual need, was also indicated as important by a substantial number of FCs.

Our study aimed to investigate factors related to FC needs, both at the beginning of SIPC and at the time the patient was dying. Regarding sociodemographic, patient- and care-related factors, multivariate regression analyses revealed that a lower education level was consistently associated with the number of very/extremely important needs (FIN-Importance). However, a higher education level had no effect on the number of met needs (FIN-Fulfillment). A recent review showed varying results regarding the impact of educational level on unmet needs of FCs [1]. The FC not being appointed as a substitute decision-maker was a factor that was consistently associated with the number of met needs (FIN-Fulfillment). The latter finding suggests that FCs who are potentially involved as surrogates in forthcoming decisions regarding patient care might experience more unmet needs. To our knowledge, this association has not been investigated in the palliative care context. In contrast to other researchers [11, 21, 23], we found a relationship neither between FC needs and being a spouse/partner nor between FC needs and patient age. Beyond sociodemographic factors, higher satisfaction with care was associated with higher numbers of met needs (FINFulfillment) at both points of time. Our results, together with those of a study by Fredriksdottir [23], demonstrate the capability of team-based, holistic SIPC to provide better need fulfillment than care in acute hospital wards [23]. Additionally, we found that stronger social support was related to a higher number of met needs (FIN-Fulfillment) at both points of time, underscoring the role of informal sources of support for meeting FCs' needs, as suggested by Aoun et al. [31]. Thus, the availability of quality SIPC and informal social support seems beneficial for fulfilling needs of FCs. Among indicators of mental burden, distress was the only factor associated with more very/extremely important needs (FIN-Importance) at the beginning of SIPC. Previous studies have shown associations of distress and psychological burden with FC needs, but these effects might be predictive in both directions $[7,11,17$, $18]$.

Despite the high number of very/extremely important needs and needs reported to be unmet, the number of FCs who had used psychosocial support services was low, with $25 \%$ using services prior to SIPC and 36\% using services during bereavement. Dionne-Odom and colleagues described a similar rate of approximately $30 \%$ of FCs of advanced cancer patients having accessed support services, but with an additional $25 \%$ of FCs who would have been interested [30]. In a study by Aoun et al., FCs also indicated that informal support by family or friends was the most frequently used form of support, followed by services offered by undertakers [32], which we did not include as an answer option. In our study, the most frequently used psychosocial support services over time were consistently psychological, spiritual and social counseling. Only approximately one-third of the FCs made use of different bereavement care programs offered by the study wards. This finding might indicate that grief work represents a very personal matter, resulting in less interest in professional than informal bereavement support. It is possible that FCs also do not feel that they are the target users of available supportive care offers. At both points in time, nonusers of support services mostly indicated that they had not accessed services due to sufficient informal support and a subjective lack of need for support (prior to SIPC: $71-84 \%$, during bereavement: 59-78\%). In comparison, structural problems, such as lack of time, lack of knowledge about services and services being too far away, were reported less often (prior to SIPC: $20-45 \%$, during bereavement: $24-28 \%$ ). Less is known about factors influencing the acceptance of bereavement support, but psychosocial support during the patient's disease seems to be used more frequently by FCs with higher psychological burden, anxiety, and depression; lower preparedness; more perceived helpfulness; and higher unmet supportive needs [11, 19, 30, 31].

\section{Limitations}

Our study has some limitations. First, the results need to be carefully interpreted in terms of possible selection bias and limitations of the generalizability of the results. Of all 693 patients admitted to the SIPC wards during the recruitment phase, the FCs of 143 of them (21\%) had to be excluded for patient-related reasons, most often due to close proximity of the patient's death. For a further 272 of 693 patients (39\%), their FCs were not eligible due to caregiver-related reasons or FCs' refusal of study participation, mostly due to high psychological burden. It is possible that non-participants may have been struggling even more, and hence, supportive care needs may be underestimated. However, research on these vulnerable FCs is sensitive, and FCs' integrity must be accommodated for ethical reasons [33]. The strengths of our study include the longitudinal design, consecutive recruitment strategy, and systematic documentation of non-participants and non-respondents.

\section{Conclusion}

In conclusion, FCs of advanced cancer patients identified a high number of very or extremely important needs at the beginning of SIPC and near the patient's death. Regarding specific needs, the importance of needs remained relatively stable over time, while changes in satisfaction with fulfillment of FCs' needs were observed in some areas. Approximately one-fourth of at least very important needs remained unmet for the majority of FCs at both assessments. Thus, a frequent 
reassessment of FC needs as well as the establishment of specific programs and services to meet the identified and unmet needs of FCs throughout the caregiving process is required. The identified factors associated with FC needs, including degree of satisfaction with care, extent of informal social support, and FC appointment as substitute decision-maker, can be used to help allocate healthcare resources to those with intensified need for support. However, only approximately onethird of FCs used information and support services prior to and during SIPC as well as in the bereavement phase. The main reason was that FCs relied on sufficient informal support and did not perceive themselves to need such services. Thus, FCs need to be better informed about the scope and beneficial effects of professional support services and how these services can complement informal support and vice versa. Furthermore, the future situation of FCs of advanced cancer patients could be improved through the provision of services tailored to FC needs as well as FC-specific written or audiovisual information, e.g., in the format of brochures, online tools, or videos. Through these strategies, FCs will be assured that their specific needs are of interest to healthcare providers; additionally, it is inevitable that FCs will need to be assured that supportive care needs are often experienced during caregiving and that many of these needs can be adequately addressed by professionals. To enhance the delivery of clinically relevant and effective supportive interventions, attention should be paid to barriers that may impede the utilization of FC-directed supportive care in the conceptualization, development, and implementation of such care.

Acknowledgments We thank all participating family caregivers, without whom this study would not have been possible. Further, we gratefully acknowledge the clinic staff for their partnership in research and for their dedicated work.

Funding information Open Access funding provided by Projekt DEAL. This study received funding by the Cancer Society of Hamburg, Germany ("Hamburger Krebsgesellschaft e.V."; no grant number assigned). The funder of the study had no role in the study design, data collection and analysis, decision to publish, or preparation of the manuscript.

Availability of data and materials The authors have full control over the primary data. The data are analyzed in this study are housed at the Palliative Care Unit, Department of Oncology, Hematology and BMT, University Medical Center Hamburg-Eppendorf, Martinistrasse 52, 20,246 Hamburg, Germany.

\section{Compliance with ethical standards}

Conflict of interest The authors declare that they have no conflict interest.

Ethical committee approval was granted by the ethics committees of the General Medical Council of Hamburg (PV5122) and the University Medical Center Goettingen (1/4/16), Germany. Written informed consent was obtained from all participants included in the study.
Open Access This article is licensed under a Creative Commons Attribution 4.0 International License, which permits use, sharing, adaptation, distribution and reproduction in any medium or format, as long as you give appropriate credit to the original author(s) and the source, provide a link to the Creative Commons licence, and indicate if changes were made. The images or other third party material in this article are included in the article's Creative Commons licence, unless indicated otherwise in a credit line to the material. If material is not included in the article's Creative Commons licence and your intended use is not permitted by statutory regulation or exceeds the permitted use, you will need to obtain permission directly from the copyright holder. To view a copy of this licence, visit http://creativecommons.org/licenses/by/4.0/.

\section{References}

1. Wang T, Molassiotis A, Chung BPM, Tan JY (2018) Unmet care needs of advanced cancer patients and their informal caregivers: a systematic review. BMC Palliat Care 17:96

2. Hwang SS, Chang VT, Alejandro Y, Osenenko P, Davis C, Cogswell J, Srinivas S, Kasimis B (2013) Caregiver unmet needs, burden, and satisfaction in symptomatic advanced cancer patients at a veterans affairs (VA) medical center. Palliat Support Care 1:319329

3. Havyer RD, van Ryn M, Wilson PM, Griffin JM (2017) The effect of routine training on the self-efficacy of informal caregivers of colorectal cancer patients. Support Care Cancer 25:1071-1077

4. Mollica MA, Litzelman K, Rowland JH, Kent EE (2017) The role of medical/nursing skills training in caregiver confidence and burden: a CanCORS study. Cancer 123:4481-4487

5. Docherty A, Owens A, Asadi-Lari M, Petchey R, Williams J, Carter YH (2008) Knowledge and information needs of informal caregivers in palliative care: a qualitative systematic review. Palliat Med 22:153-171

6. Chen SC, Chiou SC, Yu CJ, Lee YH, Liao WY, Hsieh PY, Jhang SY, Lai YH (2016) The unmet supportive care needs-what advanced lung cancer patients' caregivers need and related factors. Support Care Cancer 24:2999-3009

7. Halkett GKB, Lobb EA, Shaw T, Sinclair MM, Miller L, Hovey E, Nowak AK (2018) Do carer's levels of unmet needs change over time when caring for patients diagnosed with high-grade glioma and how are these needs correlated with distress? Support Care Cancer 26:275-286

8. Hebert RS, Schulz R, Copeland VC, Arnold RM (2009) Preparing family caregivers for death and bereavement. Insights from caregivers of terminally ill patients. J Pain Symptom Manag 37:3-12

9. Scaratti C, Leonardi M, Saladino A, Anghileri E, Broggi M, Lamperti E, Fariselli L, Ayadi R, Tringali G, Schiavolin S (2017) Needs of neuro-oncological patients and their caregivers during the hospitalization and after discharge: results from a longitudinal study. Support Care Cancer 25:2137-2145

10. Rosenberger C, Höcker A, Cartus M, Schulz-Kindermann F, Härter M, Mehnert A (2012) Outpatient psycho-oncological care for family members and patients: access, psychological distress and supportive care needs. Psychother Psychosom Med Psychol 62:185194

11. Janda M, Steginga S, Dunn J, Langbecker D, Walker D, Eakin E (2008) Unmet supportive care needs and interest in services among patients with a brain tumour and their carers. Patient Educ Couns 71:251-258

12. Fringer A, Hechinger M, Schnepp W (2018) Transitions as experienced by persons in palliative care circumstances and their families - a qualitative meta-synthesis. BMC Palliat Care 17:22 
13. Hashemi M, Irajpour A, Taleghani F (2018) Caregivers needing care: the unmet needs of the family caregivers of end-of-life cancer patients. Support Care Cancer 26:759-766

14. Harrop E, Byrne A, Nelson A (2014) "It's alright to ask for help": findings from a qualitative study exploring the information and support needs of family carers at the end of life. BMC Palliat Care 13:22

15. Aoun SM, Rumbold B, Howting D, Bolleter A, Breen LJ (2017) Bereavement support for family caregivers: the gap between guidelines and practice in palliative care. PLoS One 12:e0184750

16. Gottschalk-Fleischer A, Köhler N, Brähler E, Mehnert A, Götze H (2019) Aftermath of death of a seriously ill family member: online survey of psychological distress and care satisfaction of relatives. Gesundheitswesen 81:106-112

17. Sharpe L, Butow P, Smith C, McConnell D, Clarke S (2005) The relationship between available support, unmet needs and caregiver burden in patients with advanced cancer and their carers. Psychooncology 14:102-114

18. Schrank B, Ebert-Vogel A, Amering M, Masel EK, Neubauer M, Watzke H, Zehetmayer S, Schur S (2016) Gender differences in caregiver burden and its determinants in family members of terminally ill cancer patients. Psychooncology 25:808-814

19. Halpern MT, Fiero MH, Bell ML (2017) Impact of caregiver activities and social supports on multidimensional caregiver burden: analyses from nationally-representative surveys of cancer patients and their caregivers. Qual Life Res 26:1587-1595

20. Foreva G, Assenova R (2014) Hidden patients: the relatives of patients in need of palliative care. J Palliat Med 17:56-61

21. Weißflog G, Hönig K, Gündel H, Lang D, Niederwieser D, Döhner H, Vogelhuber M, Mehnert A, Ernst J (2017) Associations between dyadic coping and supportive care needs: findings from a study with hematologic cancer patients and their partners. Support Care Cancer 25:1445-1454

22. Bleidorn J, Pahlow H, Klindtworth K, Schneider N (2012) End-oflife care: experiences and expectations of bereaved relatives. Dtsch Med Wochenschr 137:1343-1348

23. Fridriksdottir N, Sigurdardottir V, Gunnarsdottir S (2006) Important needs of families in acute and palliative care settings assessed with the family inventory of needs. Palliat Med 20:425432

24. Perner A, Köhler N, Brähler E, Götze H (2012) Quality of life and satisfaction of family caregivers in palliative care - results of postmortem interviews with bereaved family members. Z Psychosom Med Psychother 58:267-281

25. Klarare A, Rasmussen BH, Fossum B, Fürst CJ, Hansson J, Hagelin CL (2017) Experiences of security and continuity of care: Patients' and families' narratives about the work of specialized palliative home care teams. Palliat Support Care 15:181-189

26. Ateș G, Ebenau AF, Busa C, Csikos Á, Hasselaar J, Jaspers B, Menten J, Payne S, Van Beek K, Varey S, Groot M, Radbruch L (2018) "never at ease" - family carers within integrated palliative care: a multinational, mixed method study. BMC Palliat Care 17:39

27. Ellington L, Cloyes KG, Xu J, Bellury L, Berry PH, Reblin M, Clayton MF (2018) Supporting home hospice family caregivers: insights from different perspectives. Palliat Support Care 16:209-219

28. Forbat L, François K, O'Callaghan L, Kulikowski J (2018) Family meetings in inpatient specialist palliative care: a mechanism to convey empathy. J Pain Symptom Manag 55:1253-1259

29. Mohammed S, Swami N, Pope A, Rodin G, Hannon B, Nissim R, Hales S, Zimmermann C (2018) "I didn't want to be in charge and yet I was": bereaved caregivers' accounts of providing home care for family members with advanced cancer. Psychooncology 27: $1229-1236$

30. Dionne-Odom JN, Applebaum AJ, Ornstein KA, Azuero A, Warren PP, Taylor RA, Rocque GB, Kvale EA, Demark-
Wahnefried W, Pisu M, Partridge EE, Martin MY, Bakitas MA (2018) Participation and interest in support services among family caregivers of older adults with cancer. Psychooncology 27:969976

31. Aoun SM, Breen LJ, White I, Rumbold B, Kellehear A (2018) What sources of bereavement support are perceived helpful by bereaved people and why? Empirical evidence for the compassionate communities approach. Palliat Med 32:1378-1388

32. Kristjanson LJ, Atwood J, Degner LF (1995) Validity and reliability of the family inventory of needs (FIN): measuring the care needs of families of advanced cancer patients. J Nurs Measure 3:109-126

33. Schur S, Neubauer M, Amering M, Ebert-Vogel A, Masel EK, Sibitz I, Watzke H, Schrank B (2015) Validation of the family inventory of needs (FIN) for family caregivers in palliative care. Palliat Support Care 13:485-491

34. Mehnert A, Müller D, Lehmann C, Koch U (2006) The German version of the NCCN distress thermometer: validation of a screening instrument for assessment of psychosocial distress in cancer patients. Z Psychiat Psych Psychother 54:213-223

35. Zwahlen D, Hagenbuch N, Carley MI, Recklitis CJ, Buchi S (2008) Screening cancer patients' families with the distress thermometer (DT): a validation study. Psycho-Oncology 17:959-966

36. Ullrich A, Ascherfeld L, Marx G, Bokemeyer C, Bergelt C, Oechsle K (2017) Quality of life, psychological burden, needs, and satisfaction during specialized inpatient palliative care in family caregivers of advanced cancer patients. BMC Palliat Care 16:31

37. Kroenke K, Spitzer RL, Williams JB (2001) The PHQ-9: validity of a brief depression severity measure. J Gen Int Med 16:606-613

38. Spitzer RL, Kroenke K, Williams JB, Lowe B (2006) A brief measure for assessing generalized anxiety disorder: the GAD-7. Arch Int Med 166:1092-1097

39. Murtagh FE, Ramsenthaler C, Firth A, Groeneveld EI, Lovell N, Simon ST, Denzel J, Guo P, Bernhardt F, Schildmann E, van Oorschot B, Hodiamont F, Streitwieser S, Higginson IJ, Bausewein C (2019) A brief, patient- and proxy-reported outcome measure in advanced illness: validity, reliability and responsiveness of the Integrated Palliative Care Outcome Scale (IPOS). Palliat Med 33:1045-1057

40. Aoun S, Bird S, Kristjanson LJ, Currow D (2010) Reliability testing of the FAMCARE-2 scale: measuring family carer satisfaction with palliative care. Palliat Med 24:674-681

41. Sewtz C, Muscheites W, Kriesen U, Grosse-Thie C, Kragl B, Panse J, Aoun S, Cella D, Junghanss C (2018) Questionnaires measuring quality of life and satisfaction of patients and their relatives in a palliative care setting-German translation of FAMCARE-2 and the palliative care subscale of FACIT-pal. Ann Palliat Med 7:420-426

42. Winkler J, Stolzenberg H (1999) Social class index in the Federal Health Survey. Gesundheitswesen 61: S178-S183

43. Schenk L, Bau AM, Borde T, Butler J, Lampert T, Neuhauser H, Razum O, Weilandt C (2006) A basic set of indicators for mapping migrant status. Recommendations for epidemiological practice. Bundesgesundheitsbl 49:853-860

44. Dalgard OS, Bjørk S, Tambs K (1995) Social support, negative life events and mental health. Br J Psychiatry 166:29-34

45. Meltzer H (2003) Development of a common instrument for mental health. In: Nosikov A, Gudex C (eds) EUROHIS: developing common instruments for health surveys. IOS Press, Amsterdam

46. Hodgkinson K, Butow P, Hunt GE, Wyse R, Hobbs KM, Wain G (2007) Life after cancer: couples' and partners' psychological adjustment and supportive care needs. Support Care Cancer 15: 405-415

Publisher's note Springer Nature remains neutral with regard to jurisdictional claims in published maps and institutional affiliations. 